\title{
501Y.V2 Spike Protein Resists the Antibody in Atomistic Simulations
}

\author{
Son Tung Ngo, ${ }^{\text {ab* }}$ \\ aLaboratory of Theoretical and Computational Biophysics, Ton Duc Thang University, Ho Chi Minh City 700000, \\ Vietnam \\ bFaculty of Applied Sciences, Ton Duc Thang University, Ho Chi Minh City 700000, Vietnam
}

\begin{abstract}
SARS-CoV-2 Spike (S) protein is a major biological target for COVID-19 vaccine design. Unfortunately, recent reports indicated that Spike (S) protein mutations can lead to antibody resistance. However, understanding the process is limited, especially at the atomic scale. The structural change of $\mathrm{S}$ protein and neutralizing antibody fragment (FAb) complexes was thus probed using molecular dynamics (MD) simulations. In particular, backbone RMSD of the 501Y.V2 complex was significantly larger than that of the WT implying a large structural change of the mutation system. Moreover, the mean of $R_{\mathrm{g}}$, CCS, and SASA are almost the same when compared two complexes, but the distribution of these values are absolutely different. Furthermore, the free energy landscape of the complexes was significantly changed when the 501Y.V2 variant was induced. The binding pose between $\mathrm{S}$ protein and FAb was thus altered. The FAb-binding affinity to $\mathrm{S}$ protein was thus reduced due to revealing over steered-MD (SMD) simulations. The observation is in good agreement with the respective experiment that the 501Y.V2 SARS-CoV-2 variant can escape from neutralizing antibody (NAb).
\end{abstract}

\section{INTRODUCTION}

Severe acute respiratory syndrome coronavirus 2 (SARSCoV-2) initially appeared from Wuhan, China in December 2019. ${ }^{1}$ The virus rapidly spreads worldwide that caused the human coronavirus disease 2019 (COVID-19) pandemic worldwide. ${ }^{1}$ Despite the huge efforts of the international community to limit the spread of SARS-CoV-2, more than 180 million people were infected within one and half years. ${ }^{2}$
The viral outbreak caused more than 3 million deaths and several global issues. The virus is a single-positive-strand ribonucleic acid (RNA) virus that viral sequence is similar to severe acute respiratory syndrome coronavirus (SARS-CoV) and Middle East respiratory syndrome coronavirus (MERS$\mathrm{CoV}) .3,4$ SARS-CoV-2 genomes, is contained from 26 to $32 \mathrm{~kb}$ in size, is encryption of more than 20 structural and nonstructural proteins. 5 These proteins arrange into four groups including spike, envelope, membrane, and nucleocapsid.6, 7 In particular, the viral $\mathrm{S}$ protein is used to bind to human angiotensin-converting-enzyme 2 (ACE2), ${ }_{8}$ SARS-CoV-2 thus uses the receptor to infects human cells. 9 It should be noted that $\mathrm{ACE}_{2}$ is available in various tissues involving the human lung, heart, and liver. ${ }^{10}$ Therefore, $\mathrm{S}$ protein is a target for neutralizing by human antibodies ${ }^{3}, 11,12$ and the protein interestingly is the biological target for the COVID19 vaccine design. ${ }^{13}$

The SARS-CoV-2 $\mathrm{S}$ trimer is folded by three monomers (cf. Figure 1), ${ }^{14}$ in which a monomer consists of two subunits including $\mathrm{S}_{1}$ and $\mathrm{S}_{2}$. S1 subunit, is the receptor binding region, contains the receptor binding domain (RBD) and Nterminal domain (NTD) (Figure 1). ${ }^{15}$ RBD facilitates the binding of $\mathrm{S}$ protein to $\mathrm{ACE}_{2}$ receptor. ${ }^{9} \mathrm{~S}_{1} \mathrm{~B}$ is thus called the receptor binding domain (RBD). RBD can identify and bind to the ACE2 receptor when it in the "up" shape. ${ }^{14}$ During the binding process, the conformation of $\mathrm{S}_{2}$ subunit is changed, resulting in SARS-CoV-2 is able to fuse with the cell membrane and to insert host cells.3, 9 The $\mathrm{S}_{2}$ subunit is thus called the membrane fusion region. ${ }^{14}$
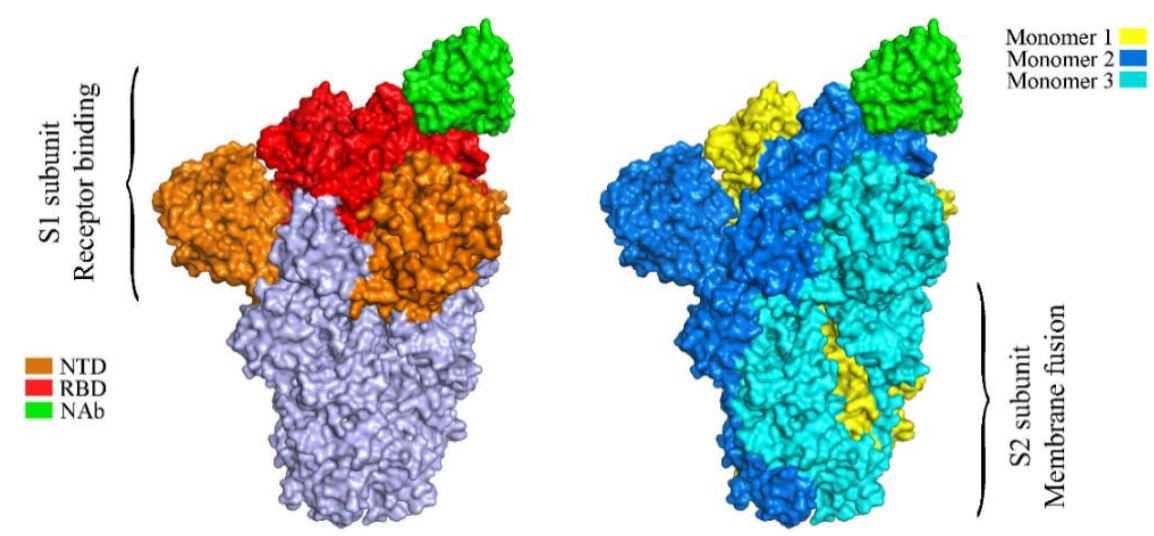

Figure 1. The conformation of the S protein + FAb complex. Three monomers were highlighted by yellow, sky blue, and cyan colors (right). The FAb was noted by green color. The N-terminal domain (NTD) and RBD were denoted by orange and red colors, respectively. 
NAbs, which can be obtained from the patient plasma or immunized laboratories, 3 mainly target RBD. These Nabs can be coarsely arranged into four classes. Classes 1 and 2 antibodies bind to RBD epitopes overlapping with the ACE2binding site. ${ }^{3}$ Directly competing with ACE2 is suggested as the neutralization mechanism of these antibodies. Immunoglobulin $\mathrm{V}$-gen segment with heavy chain complementarity determining regions $(\mathrm{CDRH})$ including $\mathrm{CDRH}_{1}, \mathrm{CDRH}_{2}$ and a short $\mathrm{CDRH}_{3}$ encodes antibodies in class 1, which are typically produced by SARS-CoV-2 infection. ${ }^{16}$ Class 2 antibodies aim to epitopes of class 1 antibodies.3, 17 Moreover, class 3 antibodies bind outside ACE2, and class 4 antibodies only aim to RBD in 'up' shape 3 and cannot prevent ACE2. Besides that, NTD of S protein is also a common target for NAbs and other monoclonal antibodies. ${ }^{18}$ These antibodies directly bind to NTD showing a large potential in COVID-19 treatment. ${ }^{17}$ The major targets of these antibodies are N1-loop (NTD N-terminus), N3-loop (supersite $\beta$-hairpin), and $\mathrm{N}_{5}$-loop (supersite loop). ${ }^{17}$

Numerous viral variants have been recently reported that can be escaped from NAbs. ${ }^{16},{ }^{19-21}$ The issues were raised because the mutations mostly appeared in the $\mathrm{S}$ protein sequence, especially in RBD. For example, in the South African (B.1.351 or 501Y.V2) variant, the mutations appeared

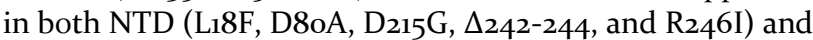
RBD $\left(\mathrm{K}_{417} \mathrm{~N}, \mathrm{E}_{4} 84 \mathrm{~K}\right.$, and $\left.\mathrm{N}_{501 \mathrm{Y}}\right) .19$ The structural change under mutation effects probably decreases the binding affinity between $\mathrm{S}$ protein and NAbs ${ }^{17}, 20,22,23$ as well as RDB and antibodies. ${ }^{24}$ The rapid transmission among communities probably generates more variants and some of them have higher toxicity, larger transmission rate, and able to escape from NAbs, etc. ${ }^{25-29}$ Decreasing NAbs efficacy probably associated with the reduction of the Covid-19 vaccine efficacy. ${ }^{26}$ Therefore, it is an emergency to understand the physical insight at the atomic level into the escape from NAbs of a new SARS-CoV-2 variant.

Studying conformations, interactions, and association/dissociation of protein-protein complexes are fundamental problems. ${ }^{30}$ It should be noted that structures of many complexes persist difficult to experimentally evaluate. ${ }^{11}, 3^{2}$ Moreover, investigating the protein-protein interactions/associations needs influential experimental tools,33, 34 but the obtained results are popularly indirect or limited. Directly determining physical insights into the protein-protein binding at an atomic level remains open problems. ${ }^{30}$ Atomistic simulations emerge as appropriate methods for evaluating the structural changes and interactions between biomolecules.35, 36 Therefore, in this work, a fragment of NAb bind to 501Y.V2/wildtype (WT) S proteins were revealed using molecular dynamics (MD) and steered-MD (SMD) simulations. Furthermore, the obtained results indicated that $501 Y . V_{2}$ complex is less stable compared with the WT one. The FAb-binding affinity to S protein is significantly decreased when the South African variant was induced. In addition, it should be noted that although glycans play an important role in the modulation of the spike conformational dynamics, ${ }^{37-39}$ glycosylation of $S$ protein was neglected to clarify the natural interaction between $\mathrm{S}$ protein + antibodies.

\section{MATERIALS \& METHODS}

\section{Structure of SARS-CoV-2 Antibodies and RBD}

The three-dimensional structure of SARS-CoV-2 S protein and $\mathrm{S}_{2} \mathrm{M} 11 \mathrm{NAb}$ fragment was download from the Protein Data Bank (PDB) with code $7 \mathrm{~K} 43 .{ }^{40}$ The complexed structure was obtained using electron microscopy method with a resolution of 2.6o $\AA$. The South African SARS-CoV-2 variant adopts eight changes in the $S$ protein. In particular, four substitutions and a deletion in NTD appeared as L18F, D8oA, D215G, $\Delta$ 242-244, and R246I. RBD had three substitutions including $\mathrm{K}_{417} \mathrm{~N}, \mathrm{E}_{4} 84 \mathrm{~K}$, and $\mathrm{N}_{501} \mathrm{Y}$. In order to generate structure of $501 Y . V_{2} \mathrm{~S}$ protein, PyMOL mutagent tool ${ }^{41}$ was thus employed to perform six substitutions including $\mathrm{L18F}$, D8oA, D215G, K417N, E484K, and N501Y. Residues L242 and A243 were also deleted using PyMOL. However, deletion $\Delta 244$ and substitution R246I were not available since the sequence $244-257$ was missed in the $7 \mathrm{~K} 43$ structure.

\section{Atomistic Simulations}

Structural change of $\mathrm{S}$ protein + FAb complexes was investigated by using atomistic simulations with the GROMACS version 5.1.5.42 The protein, FAb, and neutralized ions were parameterized via the Amber99SB-iLDN force field, 43 according to the previous works. ${ }^{44-46}$ Besides that, the complex was inserted into a water box, in which water molecules were parameterized via the $\mathrm{TIP}_{3} \mathrm{P}$ water model.47 In particular, the dodecahedron periodic boundary conditions (PBC) and rectangular PBC boxes were used in simulating the solvated complex with $\mathrm{MD}$ and SMD simulations, respectively. The size of the dodecahedron PBC box is $6311.26 \mathrm{~nm}^{3}$ with a box vector of $(20.74,20.74,20.74)$ $\mathrm{nm}$ and the size of the rectangular PBC box is $5397.98 \mathrm{~nm}^{3}$ with a box vector of $(15.59,14.54,23.80) \mathrm{nm}$. 10 and $1 \mathrm{Na}^{+}$ions were added to neutralize the WT and 501Y.V2 S protein + FAb complexes, respectively. More details about systemic configurations were shown in Figure 2.

(A)
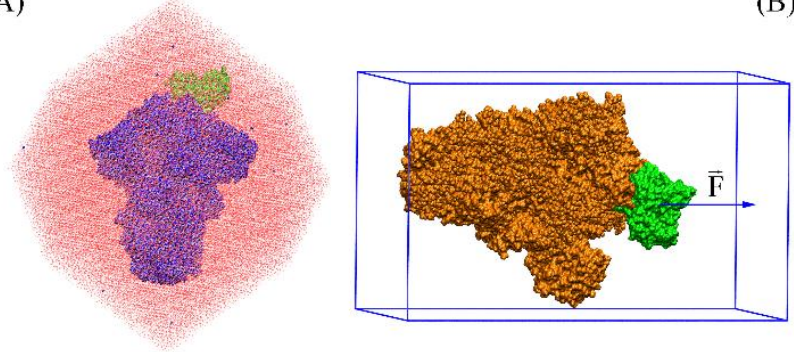

Figure 2. Initial conformations of SARS-CoV-2 S protein + FAb complexes in (A) MD and (B) SMD simulations. S protein was highlighted using blue and orange colors in (A) and (B), respectively. FAb was denoted using green color. The blue balls represent neutralized $\mathrm{Na}^{+}$ions. The solvation was hidden from (B) to provide a clarifier view.

MD simulations. MD simulations were performed using parameters, which was referred to the prior studies. ${ }^{48,} 49$ However, the integral steps were attempted every 3 femtoseconds. A non-bonded pair between two atoms was available if the spacing was smaller than $0.9 \mathrm{~nm}$. The electrostatic interaction was mimicked using the fast Particle-Mesh Ewald approach. $5^{\circ}$ The van der Waals (vdW) interaction was calculated via the cut-off scheme.

Initially, the SARS-CoV-2 S protein + FAb in solution was minimized by using steepest descent approach. The energy minimized complex was positionally restrained by NVT and NPT simulations in a short interval (100 ps each). During relaxed simulations, the integral steps were performed every 
1 femtosecond. The equilibrium conformations, which were obtained via NPT simulations, were used as initial shapes of MD simulations. The MD simulations were carried out 4 independent times with a length of $100 \mathrm{~ns}$.

SMD simulations. MD-refined structures of S protein + FAb complexes, which were obtained via free energy landscape and clustering analyses, were used as starting conformations of SMD simulations. The systems were reinsert into rectangular PBC box (Figure 2), which size was reported above, to reduce the computing times. During SMD simulations, the FAb was dissociated from $\mathrm{S}$ protein under the effects of a harmonic pulling force as mentioned in Figure 2. The pulling force was applied on the FAb center of mass with an external force using cantilever $k=1000 \mathrm{~kJ}$ $\mathrm{mol}^{-1} \mathrm{~nm}^{-2}$ and constant velocity $v=0.001 \mathrm{~nm} \mathrm{ps}^{-1}$ referring to the recent work. ${ }^{24}$ It should be noted that the $C_{\alpha}$ atoms was weakly constrained via a harmonic force. The data was recorded every 33 integral steps.

\section{Analyzed Tools}

The MD-refined structures, as well as representative structures, were obtained using a combination of the free energy landscape (FEL) and clustering method.51 FEL was constructed using the principal component analysis (PCA) approach, in which first and second eigenvectors were computed using "gmx anaeig" tool. A non-bonded (NB) contact was recorded when the spacing between two heavy atoms is within a range of $4.5 \AA$. A hydrogen bond (HB) contact was measured when the angle $\angle \mathrm{D}-\mathrm{H}-\mathrm{A}$ is larger than $135^{\circ}$ and the spacing $\mathrm{D}-\mathrm{A}$ is within a range of $3.5 \AA$, whereas $\mathrm{D}$ is donor, $\mathrm{H}$ is hydrogen, and $\mathrm{A}$ is acceptor. The solvent accessible surface area (SASA) and gyration of radius $R_{\mathrm{g}}$ were estimated via using "gmx sasa" and "gmx sasa" tools, respectively. The collision cross section (CCS) were determined via ion mobility projection approximation calculation tool (IMPACT) protocol..$^{2}$

\section{RESULTS AND DISCUSSION}

As mentioned above, the protein-protein association is a fundamental problem. $3^{3}$ Protein-protein association or dissociation processes are hard to directly determine in experiments. ${ }^{31-34}$ In this work, atomistic MD simulations were employed to clarify the physical insights into the binding process between $\mathrm{S}$ protein and FAb. The structural change of the complexes was easily monitored over simulation trajectories.37, 53, 54 The backbone root-meansquare deviation (RMSD) of the complexes suggested that systems mostly reached equilibrium states after $40 \mathrm{~ns}$ of MD simulations (Figures $\mathrm{S}_{1}-\mathrm{S}_{2}$ of the Supporting Information). Structural analyses were then carried out over equilibrium intervals of S protein + FAb complexes.

Structural metrics of complexes including backbone RMSD, $R_{\mathrm{g}}$, SASA, and CCS were analyzed in detail. The distribution of these values was reported in Figure 3. In particular, the 501Y.v2 variant enlarged the backbone RMSD of the complex (cf. Figure $3 \mathrm{~A}$ ), in which the corresponding values of WT and 501Y.V2 systems formed averages of $0.31 \pm$
0.03 and $0.38 \pm 0.05 \mathrm{~nm}$, respectively. The averaged $R_{\mathrm{g}}$ of two complexes are almost similar with amounts of $5.13 \pm 0.02$ (WT) and $5.12 \pm 0.03$ (501Y.V2), but the $501 Y . V_{2} R_{\mathrm{g}}$ is more diffusion than WT one (Figure $3 \mathrm{~B}$ ). The mean CCS of WT and $501 Y . V_{2}$ systems are $134.47 \pm 0.80$ and $134.37 \pm 1.64 \mathrm{~nm}^{2}$, respectively. Although the average value of CCS is not different, the form of CCS curve was significantly altered as well as RMSD curve (cf. Figure ${ }_{3} \mathrm{C}$ ). Moreover, it is consistent with the larger RMSD of 501Y.V2 were observed, the mean of total SASA is of $1400 \pm 9$ (WT) and $1403 \pm 20$ (501Y.V2) nm² (Figure $3 \mathrm{D})$. The observations suggested that the complex structure of 501Y.V2 S protein + FAb was significantly altered in comparison with the WT system.
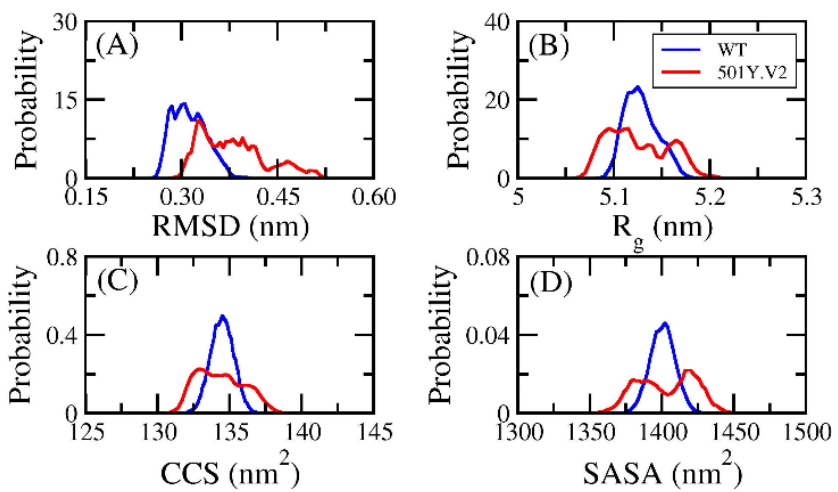

Figure 3. Comparison of measured metrics between WT (blue) and 501Y.V2 (red) systems. In particular, (A) is backbone RMSD of two complexes; $(\mathrm{B})$ is the gyration of radius of two systems; (C) is CCS of complexes; (D) is SASA of complexes.

The $C_{\alpha}$ atoms root-mean-square fluctuation (RMSF) of the complexes were investigated over equilibrium MD domains. The results are shown in Figure 4, in which the fluctuation of $S$ protein was averaged over three chains. Two chains of FAb are asymmetric each other, so the $C_{\alpha}$ RMSF results were presented to all chains. The $C_{\alpha}$ RMSF of $S$ protein can roughly arrange into two domains corresponding to $S_{1}$ and S2 domains. As shown in Figure 4, $C_{\alpha}$ RMSF of $S_{1}$ domain is significantly larger than that of $\mathrm{S}_{2}$ domain. Moreover, the 501Y.V2 $\mathrm{S}$ protein is more flexible than WT system since forming a larger $C_{\alpha}$ RMSF along the sequences. Especially, the RBD region of the South African variant much changed under the effects of three substitutions. In particular, the residue K417 adopted a $C_{\alpha}$ RMSF of $0.22 \pm 0.02 \mathrm{~nm}$, which is significantly smaller than that of residue $\mathrm{K}_{417} \mathrm{~N}(0.33 \pm 0.08$ $\mathrm{nm})$. While the residue $\mathrm{E}_{4} 84$ fluctuates with a $C_{\alpha}$ RMSF of $0.28 \pm 0.04 \mathrm{~nm}$, the residue $\mathrm{E} 484 \mathrm{~K}$ changes with a $C_{\alpha} \mathrm{RMSF}$ of $0.55 \pm 0.06 \mathrm{~nm}$. In similar, N501Y formed a larger $C_{\alpha}$ RMSF $(0.43 \pm 0.10 \mathrm{~nm})$ compared with $\mathrm{N}_{501}(0.25 \pm 0.04 \mathrm{~nm})$. Furthermore, the fluctuation of $501 Y . V_{2} \mathrm{~S}$ protein also turns the structure of FAb to becomes more flexible with the mean $C_{\alpha}$ RMSF of $0.39 \pm 0.08 \mathrm{~nm}$ in comparison with the mean WT $C_{\alpha}$ RMSF of $0.26 \pm 0.06 \mathrm{~nm}$. 


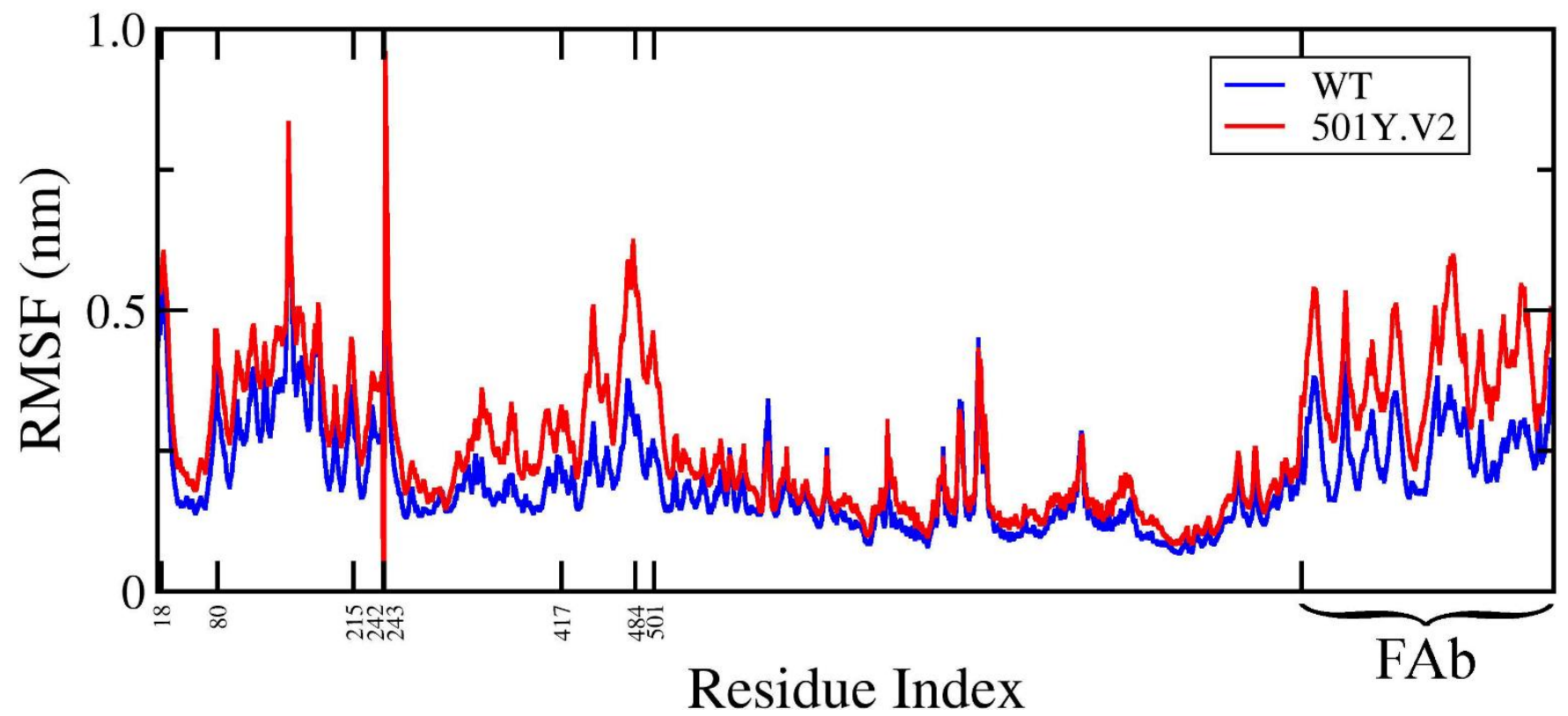

Figure 4. $C_{\alpha}$ RMSF of SARS-CoV-2 S protein + FAb over equilibrium trajectories. Noted residues are substitutions or deletions in 501Y.V2 variant.

The stable conformation of the complexes can be probed using two-dimensional FEL analysis, which was constructed using "gmx sham" tool51, 55 with two coordinates were first and second eigenvectors. Complexes eigenvectors were calculated using the principal component analysis (PCA) method. ${ }^{1,}, 55$ The PCA method was used to generate $2 \mathrm{D}$ FEL in order to probe the conformational alterations of $S$ protein + FAb complexes. The obtained FEL were displayed in Figure 5. Although the minima amounts are different with $\mathrm{RBD}+\mathrm{NAb}$ complexes, ${ }^{24}$ the general picture is almost similar that the 501Y.v2 variant still increases the number of FEL minima of S protein + FAb complex. It probably implies that the 501Y.V2 complex is less stable than the WT one. This is in good agreement with a comparison of the backbone RMSD distribution of WT and 501Y.V2 systems above (cf. Figure 3). Therefore, it may argue that the binding affinity of FAb to $\mathrm{S}$ protein probably decreases when the 501Y.V2 variant was induced.
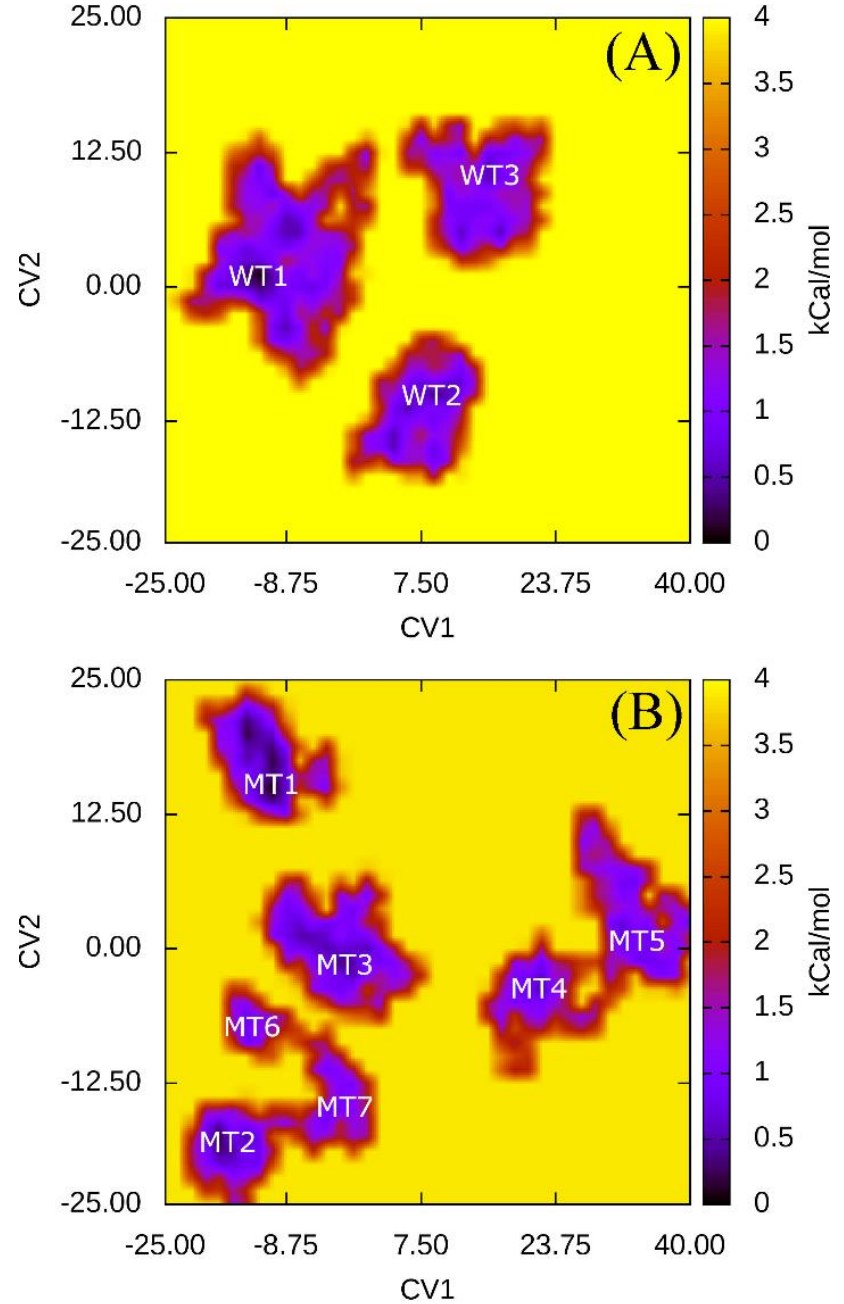

Figure 5. Free energy landscape of SARS-CoV-2 S protein + $\mathrm{NAb}$ was constructed using PCA method, in which (A) . In particular, (A) and (B) interpret the WT and 501Y.V2 systems, respectively. 
FEL of S protein + FAb formed more minima when 501Y.V2 variant was induced. In particular, FEL of WT S protein + FAb formed three minima denoted as $\mathbf{W T} \mathbf{1}, \mathbf{W T} \mathbf{2}$, and $\mathbf{W T}_{\mathbf{3}}$ in Figure 5 Figure 5, which is located at $\left(\mathrm{CV}_{1} ; \mathrm{CV}_{2}\right)$ coordinates of (-12.81; 0.63), (8.31; -10.63), and (14.81; 10.00), respectively. The populations of three minima were of 50, 25, and $25 \%$ corresponding to minima WT1, WT2, and $\mathbf{W T}_{\mathbf{3}}$ (cf. Table 1), respectively. Besides, FEL of 501Y.V2 S protein +
FAb adopted seven minima noted as MT1, MT2, MT $3, \mathbf{M T}_{4}$, MT5, MT6, and $\mathbf{M T}_{7}$, which is located at $\left(\mathrm{CV}_{\mathbf{1}} ; \mathrm{CV}_{2}\right)$ coordinates at (-11.19; 14.38), (-17.69; -18.13), (-3.06; -1.88), (21.31; -4.38), (31.06; 1.25), (-14.44; -8.13), and (-3.88; -16.25), respectively. The populations of seven minima were mentioned in Table $\mathbf{1}$, in which the minima $\mathbf{M T}_{\mathbf{3}}$ formed the largest populations and the minima MT6 adopted the smallest populations.

Table 1. Detailed information of representative structures of WT/501Y.V2 S protein + FAb and SMD results. ${ }^{a}$

\begin{tabular}{cccccccc}
\hline No & System & Population & $\boldsymbol{R}_{\mathbf{g}}$ & CCS & SASA & $\boldsymbol{F}_{\text {Max }}$ & $\boldsymbol{W}$ \\
1 & WT1 & 50 & 5.12 & 134.86 & 1410 & $1145.1 \pm 27.3$ & $150.6 \pm 4.9$ \\
2 & WT2 & 25 & 5.12 & 134.24 & 1416 & $947.4 \pm 16.3$ & $129.7 \pm 4.1$ \\
3 & WT3 & 25 & 5.16 & 134.31 & 1397 & $1174.1 \pm 39.8$ & $165.7 \pm 5.6$ \\
4 & MT1 & 24 & 5.10 & 132.85 & 1373 & $1006.6 \pm 37.6$ & $142.1 \pm 5.3$ \\
5 & MT2 & 14 & 5.07 & 132.54 & 1372 & $1049.0 \pm 32.3$ & $131.2 \pm 5.3$ \\
6 & MT3 & 26 & 5.14 & 133.73 & 1424 & $1064.5 \pm 29.7$ & $131.6 \pm 5.2$ \\
7 & MT4 & 9 & 5.15 & 136.63 & 1413 & $1056.4 \pm 56.9$ & $137.0 \pm 5.8$ \\
8 & MT5 & 16 & 5.17 & 136.79 & 1423 & $1048.8 \pm 15.1$ & $139.8 \pm 3.6$ \\
9 & MT6 & 4 & 5.11 & 133.82 & 1394 & $799.4 \pm 26.9$ & $94.8 \pm 4.3$ \\
10 & MT7 & 7 & 5.12 & 133.10 & 1398 & $1123.2 \pm 16.4$ & $134.5 \pm 5.9$ \\
\hline
\end{tabular}

aThe computed error is the standard error of the mean.

The representative structures of reported minima were then obtained by using the clustering method with a nonhydrogen cut-off of $0.2 \mathrm{~nm} . .^{1,56}$ The obtained structures were reported in Figure 6. Moreover, the structural information as $R_{\mathrm{g}}$, CCS, and SASA was described in Table $\mathbf{1}$. In good consistent with the metric analyses above, the WT and 501Y.V2 complexes formed a similar gyration of radius and CCS, but the SASA of the WT system is slightly larger than that of $501 Y . V_{2}$ one. These conformations were then employed as starting conformations for SMD simulations. The binding affinity between $\mathrm{FAb}$ and $\mathrm{S}$ protein was thus revealed. However, it should keep in mind that the simulated PBC box was changed to a rectangular PBC in order to save computing resources as mentioned above.
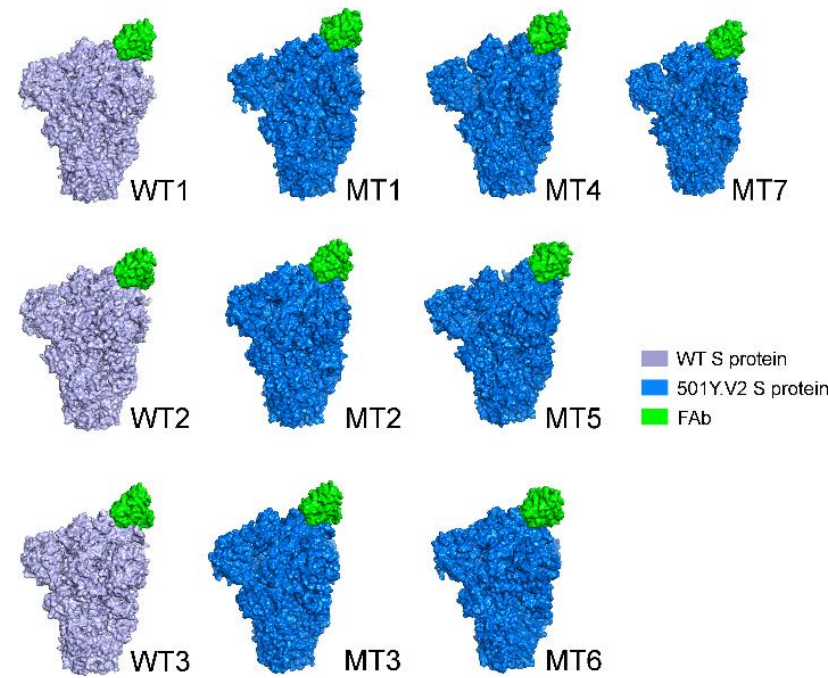

Figure 6. Representative structures of WT and 501Y.V2 S protein + FAb.

In order to probe the binding affinity between two biomolecules, numerous approaches were developed such as perturbation free energy, 57 thermodynamics integration, ${ }^{88,59}$ molecular mechanics/Poisson-Boltzmann surface area, ${ }^{60,}{ }^{61}$ umbrella sampling (US), ${ }^{24}$ a combination of perturbation simulations and US, ${ }^{62}$ and enhanced sampling implementation of perturbation simulations. ${ }^{63}$ However, unfortunately, the $S$ protein + FAb complex is a large system comprising more than a half-million atoms, it would be thus required huge computing resources if these approaches were applied. In that context, SMD simulations emerge as a potential approach to complete task force since requiring a small among of computing resources. ${ }^{24}, 64$

The antibody FAb was dissociated from the $\mathrm{S}$ protein using SMD simulations according to the recent work. ${ }^{24}$ The binding affinity of FAb to $\mathrm{S}$ protein was thus probed with an assumption that a stronger binder corresponds to a larger rupture force or pulling work system. The representative conformations of $\mathrm{S}$ protein $+\mathrm{FAb}$ provided by MD simulations were used as initial structures for SMD investigations. Because the complexes were reinserted to the new water box, these systems were first optimized using energy minimization and then relaxed using short NVT and NPT simulations. The protein coordinates were positionally retrained during these simulations. FAb was forced to mobilize from bound to unbound states via $2.5 \mathrm{~ns}$ of SMD simulations (cf. Figures $\mathrm{S}_{3}-\mathrm{S}_{12}$ of the Supporting Information). The obtained rupture force and pulling work were shown in Table 1. In particular, the form of pulling force curve is in good consistent with the previous works, ${ }^{24}$, 64-66 in which the pulling force is linearly increased to the maximum value, $F_{\text {Max }}$, then rapidly decreased to zero. The average of $F_{\text {Max }}$ and $W$ was then calculated upon the population of the representative structures. The WT system adopted a mean value of $\left\langle F_{\text {Max }}\right\rangle=1102.9 \pm 27.6 \mathrm{pN}$ and $\langle W\rangle=149.1 \pm 4.9 \mathrm{kcal} \mathrm{mol}^{-1}$, which is significantly larger than that of the 501Y.V2 system forming a value of $\left\langle F_{\mathrm{Max}}\right\rangle=$

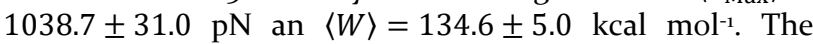
obtained results imply that FAb formed a poorer binding 
affinity to $501 Y . V_{2} \mathrm{~S}$ protein that is in good agreement with the recent experiments. ${ }^{19,}$, 20

\section{CONCLUSIONS}

The structural conformations of the WT and 501Y.V2 S protein + FAb complexes were probed using atomistic MD simulations. The $501 Y . V_{2} \mathrm{~S}$ protein + FAb structure is more flexible than the WT system. In particular, backbone RMSD of the 501Y.V2 complex was significantly larger than that of the WT implying a large structural change of the mutation system. The mean of other metrics as well as $R_{\mathrm{g}}$, CCS, and SASA are almost the same when compared two complexes, but the distribution of these values are clearly different. Moreover, the structural changes are clearly reflected in the FEL analysis, in which the number of FEL minima of the 501Y.V2 complex is much larger than that of the WT system. The population of the minima was also changed under the effects of the mutations. Furthermore, the binding affinity of $\mathrm{FAb}$ to $\mathrm{S}$ protein is then revealed using SMD simulations, which is starting from the representative structure of the complexes. The 501Y.V2 $\mathrm{S}$ protein was found to be formed a smaller binding affinity to FAb compared with the WT one that is in good agreement with the recent observations. ${ }^{19}, 20$, ${ }^{22}$ In addition, it may argue that the SMD simulations would be potential approach to reveal the binding process between two proteins.

\section{ASSOCIATED CONTENT}

\section{Data and Software Availability}

All relevant data to necessary to reproduce all results in the paper are within the main text and the Supporting Information. Input files and MD parameters for running calculations are included in the Supporting Information.

\section{Supporting Information}

Supporting Information Available: backbone RMSD of S protein + FAb systems; pulling forces over 8 independent SMD trajectories, in which initial conformations were WT1, $\mathrm{WT}_{2}, \mathrm{WT}_{3}, \mathrm{MT} 1, \mathrm{MT}_{2}, \mathrm{MT}_{3}, \mathrm{MT}_{4}, \mathrm{MT}_{5}, \mathrm{MT} 6$, and $\mathrm{MT}_{7}$ conformations. The material is available free of charge via the Internet at http://pubs.acs.org.

\section{AUTHOR INFORMATION}

\section{Corresponding Author}

*Email: ngosontung@tdtu.edu.vn

\section{Author Contributions}

All authors contributed to doing computations and preparing the manuscript.

\section{Notes}

The authors declare no competing financial interests. ACKNOWLEDGMENT

This work was supported by Vietnam National Foundation for Science \& Technology Development (NAFOSTED) grant \#104.99-2019.57.

\section{REFERENCES}

1. WHO Coronavirus disease (COVID-19) outbreak. https://www.who.int/emergencies/diseases/novelcoronavirus-2019 (accessed May 11, 2021).

2. worldometrics COVID-19 Coronavirus Pandemic. https://www.worldometers.info/coronavirus/.
3. Barnes, C. O.; West, A. P.; Huey-Tubman, K. E.; Hoffmann, M. A. G.; Sharaf, N. G.; Hoffman, P. R.; Koranda, N.; Gristick, H. B.; Gaebler, C.; Muecksch, F.; Lorenzi, J. C. C.; Finkin, S.; Hägglöf, T.; Hurley, A.; Millard, K. G.; Weisblum, Y.; Schmidt, F.; Hatziioannou, T.; Bieniasz, P. D.; Caskey, M.; Robbiani, D. F.; Nussenzweig, M. C.; Bjorkman, P. J., Structures of Human Antibodies Bound to SARS-CoV-2 Spike Reveal Common Epitopes and Recurrent Features of Antibodies. Cell 2020, 182 (4), 828-842.e16.

4. $\quad$ de Wit, E.; van Doremalen, N.; Falzarano, D.; Munster, V. J., SARS and MERS: recent insights into emerging coronaviruses. Nature Reviews Microbiology 2016, 14 (8), 523-534.

5. Francés-Monerris, A.; Hognon, C.; Miclot, T.; García-Iriepa, C.; Iriepa, I.; Terenzi, A.; Grandemange, S.; Barone, G.; Marazzi, M.; Monari, A., Molecular Basis of SARSCoV-2 Infection and Rational Design of Potential Antiviral Agents: Modeling and Simulation Approaches. J. Proteome Res. 2020, 19 (11), 4291-4315.

6. Ngo, S. T.; Quynh Anh Pham, N.; Thi Le, L.; Pham, D.-H.; Vu, V. V., Computational Determination of Potential Inhibitors of SARS-CoV-2 Main Protease. Journal of Chemical Information and Modeling 2020, 60 (12), 5771-5780.

7. Schoeman, D.; Fielding, B. C., Coronavirus envelope protein: current knowledge. Virology Journal 2019, 16 (1), 69.

8. $\quad$ Yang, J.; Petitjean, S. J. L.; Koehler, M.; Zhang, Q.; Dumitru, A. C.; Chen, W.; Derclaye, S.; Vincent, S. P.; Soumillion, P.; Alsteens, D., Molecular Interaction and Inhibition of SARS-CoV-2 Binding to the ACE2 Receptor. Nat Commun 2020, 11 (1), 4541.

9. $\quad$ Lan, J.; Ge, J.; Yu, J.; Shan, S.; Zhou, H.; Fan, S.; Zhang, Q.; Shi, X.; Wang, Q.; Zhang, L.; Wang, X., Structure of the SARS-CoV-2 spike receptor-binding domain bound to the ACE2 receptor. Nature 2020, 581 (7807), 215-220.

10. Hoffmann, M.; Kleine-Weber, H.; Schroeder, S.; Kruger, N.; Herrler, T.; Erichsen, S.; Schiergens, T. S.; Herrler, G.; Wu, N. H.; Nitsche, A.; Muller, M. A.; Drosten, C.; Pohlmann, S., SARS-CoV-2 Cell Entry Depends on ACE2 and TMPRSS2 and Is Blocked by a Clinically Proven Protease Inhibitor. Cell 2020.

11. Ju, B.; Zhang, Q.; Ge, J.; Wang, R.; Sun, J.; Ge, X.; Yu, J.; Shan, S.; Zhou, B.; Song, S.; Tang, X.; Yu, J.; Lan, J.; Yuan, J.; Wang, H.; Zhao, J.; Zhang, S.; Wang, Y.; Shi, X.; Liu, L.; Zhao, J.; Wang, X.; Zhang, Z.; Zhang, L., Human Neutralizing Antibodies Elicited by SARS-CoV-2 Infection. Nature 2020, 584 (7819), 115-119.

12. Kim, S. I.; Noh, J.; Kim, S.; Choi, Y.; Yoo, D. K.; Lee, Y.; Lee, H.; Jung, J.; Kang, C. K.; Song, K.-H.; Choe, P. G.; Kim, H. B.; Kim, E. S.; Kim, N.-J.; Seong, M.-W.; Park, W. B.; Oh, M.d.; Kwon, S.; Chung, J., Stereotypic Neutralizing $V_{H}$ Antibodies Against SARS-CoV-2 Spike Protein Receptor Binding Domain in Patients with COVID-19 and Healthy Individuals. Sci. Transl. Med. 2021, 13 (578), eabd6990.

13. COVID-19 Vaccines.

https://www.fda.gov/emergency-preparedness-andresponse/coronavirus-disease-2019-covid-19/covid-19vaccines (accessed Jan 08).

14. Yang, Y.; Du, L., SARS-CoV-2 Spike Protein: a Key Target for Eliciting Persistent Neutralizing Antibodies. Sig Transduct Target Ther 2021, 6 (1), 95.

15. Huang, Y.; Yang, C.; Xu, X.-f.; Xu, W.; Liu, S.-W., Structural and functional properties of SARS-CoV-2 spike protein: potential antivirus drug development for COVID-19. Acta Pharmacol Sin 2020, 41 (9), 1141-1149.

16. Chen, R. E.; Zhang, X.; Case, J. B.; Winkler, E. S.; Liu, Y.; VanBlargan, L. A.; Liu, J.; Errico, J. M.; Xie, X.; Suryadevara, 
N.; Gilchuk, P.; Zost, S. J.; Tahan, S.; Droit, L.; Turner, J. S.; Kim, W.; Schmitz, A. J.; Thapa, M.; Wang, D.; Boon, A. C. M.; Presti, R. M.; O’Halloran, J. A.; Kim, A. H. J.; Deepak, P.; Pinto, D.; Fremont, D. H.; Crowe, J. E.; Corti, D.; Virgin, H. W.; Ellebedy, A. H.; Shi, P.-Y.; Diamond, M. S., Resistance of SARSCoV-2 variants to neutralization by monoclonal and serumderived polyclonal antibodies. Nat Med 2021, 27 (4), 717726.

17. Wibmer, C. K.; Ayres, F.; Hermanus, T.; Madzivhandila, M.; Kgagudi, P.; Oosthuysen, B.; Lambson, B. E.; de Oliveira, T.; Vermeulen, M.; van der Berg, K.; Rossouw, T.; Boswell, M.; Ueckermann, V.; Meiring, S.; von Gottberg, A.; Cohen, C.; Morris, L.; Bhiman, J. N.; Moore, P. L., SARSCoV-2 501Y.V2 escapes neutralization by South African COVID-19 donor plasma. Nature Medicine 2021.

18. Liu, L.; Wang, P.; Nair, M. S.; Yu, J.; Rapp, M.; Wang, Q.; Luo, Y.; Chan, J. F. W.; Sahi, V.; Figueroa, A.; Guo, X. V.; Cerutti, G.; Bimela, J.; Gorman, J.; Zhou, T.; Chen, Z.; Yuen, K.-Y.; Kwong, P. D.; Sodroski, J. G.; Yin, M. T.; Sheng, Z.; Huang, Y.; Shapiro, L.; Ho, D. D., Potent neutralizing antibodies against multiple epitopes on SARS-CoV-2 spike. Nature 2020, 584 (7821), 450-456.

19. Weisblum, Y.; Schmidt, F.; Zhang, F.; DaSilva, J.; Poston, D.; Lorenzi, J. C. C.; Muecksch, F.; Rutkowska, M.; Hoffmann, H.-H.; Michailidis, E.; Gaebler, C.; Agudelo, M.; Cho, A.; Wang, Z.; Gazumyan, A.; Cipolla, M.; Luchsinger, L.; Hillyer, C. D.; Caskey, M.; Robbiani, D. F.; Rice, C. M.; Nussenzweig, M. C.; Hatziioannou, T.; Bieniasz, P. D., Escape from neutralizing antibodies by SARS-CoV-2 spike protein variants. elife 2020, 9, e61312.

20. Hoffmann, M.; Arora, P.; Groß, R.; Seidel, A.; Hörnich, B. F.; Hahn, A. S.; Krüger, N.; Graichen, L.; HofmannWinkler, H.; Kempf, A.; Winkler, M. S.; Schulz, S.; Jäck, H.-M.; Jahrsdörfer, B.; Schrezenmeier, H.; Müller, M.; Kleger, A.; Münch, J.; Pöhlmann, S., SARS-CoV-2 Variants B.1.351 and P.1 Escape from Neutralizing Antibodies. Cell 2021.

21. Hoffmann, M.; Hofmann-Winkler, H.; Krüger, N.; Kempf, A.; Nehlmeier, I.; Graichen, L.; Sidarovich, A.; Moldenhauer, A.-S.; Winkler, M. S.; Schulz, S.; Jäck, H.-M.; Stankov, M. V.; Behrens, G. M. N.; Pöhlmann, S., SARS-CoV-2 variant B.1.617 is resistant to Bamlanivimab and evades antibodies induced by infection and vaccination. bioRxiv 2021, 2021.05.04.442663.

22. Wang, P.; Nair, M. S.; Liu, L.; Iketani, S.; Luo, Y.; Guo, Y.; Wang, M.; Yu, J.; Zhang, B.; Kwong, P. D.; Graham, B. S.; Mascola, J. R.; Chang, J. Y.; Yin, M. T.; Sobieszczyk, M.; Kyratsous, C. A.; Shapiro, L.; Sheng, Z.; Huang, Y.; Ho, D. D., Antibody Resistance of SARS-CoV-2 Variants B.1.351 and B.1.1.7. Nature 2021.

23. Cele, S.; Gazy, I.; Jackson, L.; Hwa, S.-H.; Tegally, H.; Lustig, G.; Giandhari, J.; Pillay, S.; Wilkinson, E.; Naidoo, Y.; Karim, F.; Ganga, Y.; Khan, K.; Bernstein, M.; Balazs, A. B.; Gosnell, B. I.; Hanekom, W.; Moosa, M.-Y. S.; Lessells, R. J.; de Oliveira, T.; Sigal, A.; Ngs, S. A.; Team, C.-K., Escape of SARSCoV-2 501Y.V2 from Neutralization by Convalescent Plasma. Nature 2021.

24. Ngo, S. T.; Nguyen, T. H.; Pham, D.-H.; Tung, N. T.; Nam, P. C., Thermodynamics and Kinetics in Antibody Resistance of the 501Y.V2 SARS-CoV-2 Variant. 2021.

25. CDC SARS-CoV-2 Variant Classifications and Definitions. $\quad$ https://www.cdc.gov/coronavirus/2019ncov/cases-updates/variant-surveillance/variant-info.html (accessed May 11, 2021).

26. CDC Science Brief: Emerging SARS-CoV-2 Variants. https://www.cdc.gov/coronavirus/2019ncov/science/science-briefs/scientific-brief-emergingvariants.html (accessed May 11, 2021).
27. WHO SARS-CoV-2 Variants. https://www.who.int/csr/don/31-december-2020-sarscov2-variants/en/ (accessed May 11, 2021).

28. Abdool Karim, S. S.; de Oliveira, T., New SARS-CoV-2 Variants - Clinical, Public Health, and Vaccine Implications. $N$ Engl J Med 2021.

29. Reuters WHO classifies India variant as being of global concern.

https://www.reuters.com/business/healthcare-

pharmaceuticals/who-designates-india-variant-beingglobal-concern-2021-05-10/ (accessed May 11, 2021).

$30 . \quad$ Pan, A. C.; Jacobson, D.; Yatsenko, K.; Sritharan, D.; Weinreich, T. M.; Shaw, D. E., Atomic-Level Characterization of Protein-Protein Association. Proc Natl Acad Sci U S A 2019, $116(10), 4244-4249$.

31. Lupardus, P. J.; Ultsch, M.; Wallweber, H.; Bir Kohli, P.; Johnson, A. R.; Eigenbrot, C., Structure of the pseudokinase-kinase domains from protein kinase TYK2 reveals a mechanism for Janus kinase (JAK) autoinhibition. Proc. Natl. Acad. Sci. U.S.A 2014, 111 (22), 8025-8030.

32. Shan, Y.; Gnanasambandan, K.; Ungureanu, D.; Kim, E. T.; Hammarén, H.; Yamashita, K.; Silvennoinen, O.; Shaw, D. E.; Hubbard, S. R., Molecular basis for pseudokinasedependent autoinhibition of JAK2 tyrosine kinase. Nat. Struct. Mol. Biol. 2014, 21 (7), 579-584.

33. Tang, C.; Iwahara, J.; Clore, G. M., Visualization of Transient Encounter Complexes in Protein-Protein Association. Nature 2006, 444 (7117), 383-386.

34. Frisch, C.; Fersht, A. R.; Schreiber, G., Experimental Assignment of the Structure of the Transition State for the Association of Barnase and Barstar. J. Mol. Biol. 2001, 308 (1), 69-77.

35. Ngo, S. T.; Derreumaux, P.; Vu, V. V., Probable Transmembrane Amyloid $\alpha$-Helix Bundles Capable of Conducting $\mathrm{Ca}^{2+}$ Ions. J. Phys. Chem. B 2019, 123 (12), 26452653.

36. Ngo, S. T.; Nguyen, P. H.; Derreumaux, P., Cholesterol Molecules Alter the Energy Landscape of Small Aß1-42 Oligomers. J. Phys. Chem. B 2021, 125 (9), 2299-2307. 37. Casalino, L.; Gaieb, Z.; Goldsmith, J. A.; Hjorth, C. K.; Dommer, A. C.; Harbison, A. M.; Fogarty, C. A.; Barros, E. P.; Taylor, B. C.; McLellan, J. S.; Fadda, E.; Amaro, R. E., Beyond Shielding: The Roles of Glycans in the SARS-CoV-2 Spike Protein. ACS Cent. Sci. 2020, 6 (10), 1722-1734.

38. Woo, H.; Park, S.-J.; Choi, Y. K.; Park, T.; Tanveer, M.; Cao, Y.; Kern, N. R.; Lee, J.; Yeom, M. S.; Croll, T. I.; Seok, C.; Im, W., Developing a Fully Glycosylated Full-Length SARSCoV-2 Spike Protein Model in a Viral Membrane. J. Phys. Chem. B 2020, 124 (33), 7128-7137.

39. Turoňová, B.; Sikora, M.; Schürmann, C.; Hagen, W. J. H.; Welsch, S.; Blanc, F. E. C.; von Bülow, S.; Gecht, M.; Bagola, K.; Hörner, C.; van Zandbergen, G.; Landry, J.; de Azevedo, N. T. D.; Mosalaganti, S.; Schwarz, A.; Covino, R.; Mühlebach, M. D.; Hummer, G.; Krijnse Locker, J.; Beck, M., In situ structural analysis of SARS-CoV-2 spike reveals flexibility mediated by three hinges. Science 2020, 370 (6513), 203.

40. Tortorici, M. A.; Beltramello, M.; Lempp, F. A.; Pinto, D.; Dang, H. V.; Rosen, L. E.; McCallum, M.; Bowen, J.; Minola, A.; Jaconi, S.; Zatta, F.; De Marco, A.; Guarino, B.; Bianchi, S.; Lauron, E. J.; Tucker, H.; Zhou, J.; Peter, A.; Havenar-Daughton, C.; Wojcechowskyj, J. A.; Case, J. B.; Chen, R. E.; Kaiser, H.; Montiel-Ruiz, M.; Meury, M.; Czudnochowski, N.; Spreafico, R.; Dillen, J.; Ng, C.; Sprugasci, N.; Culap, K.; Benigni, F.; Abdelnabi, R.; Foo, S.-Y.C.; Schmid, M. A.; Cameroni, E.; Riva, A.; Gabrieli, A.; Galli, M.; Pizzuto, M. S.; Neyts, J.; Diamond, M. S.; Virgin, H. W.; Snell, G.; Corti, D.; Fink, K.; Veesler, D., Ultrapotent Human Antibodies 
Protect Against SARS-CoV-2 Challenge via Multiple Mechanisms. Science 2020, 370 (6519), 950-957.

41. Schrödinger LLC, P. The PyMOL Molecular Graphics System, Version 1.3r1; August, 2010.

42. Abraham, M. J.; Murtola, T.; Schulz, R.; Páll, S.; Smith, J. C.; Hess, B.; Lindahl, E., GROMACS: High Performance Molecular Simulations through Multi-Level Parallelism from Laptops to Supercomputers. SoftwareX 2015, 1-2, 19-25.

43. Aliev, A. E.; Kulke, M.; Khaneja, H. S.; Chudasama, V.; Sheppard, T. D.; Lanigan, R. M., Motional Timescale Predictions by Molecular Dynamics Simulations: Case Study using Proline and Hydroxyproline Sidechain Dynamics. Proteins: Struct., Funct., Bioinf. 2014, 82 (2), 195-215.

44. Zhang, H.; Yin, C.; Jiang, Y.; van der Spoel, D., Force Field Benchmark of Amino Acids: I. Hydration and Diffusion in Different Water Models. J. Chem. Inf. Model. 2018, 58 (5), 1037-1052.

45. Zhang, H.; Jiang, Y.; Cui, Z.; Yin, C., Force Field Benchmark of Amino Acids. 2. Partition Coefficients between Water and Organic Solvents. J. Chem. Inf. Model. 2018, 58 (8), 1669-1681.

46. Ngo, S. T.; Nguyen, P. H.; Derreumaux, P., Impact of the Rat R5G, Y10F, and H13R Mutations on Tetrameric A 342 $\beta$-Barrel in a Lipid Bilayer Membrane Model. J. Phys. Chem. B 2021, 125 (12), 3105-3113.

47. Jorgensen, W. L.; Chandrasekhar, J.; Madura, J. D.; Impey, R. W.; Klein, M. L., Comparison of Simple Potential Functions for Simulating Liquid Water. J. Chem. Phys. 1983, 79 (2), 926-935.

48. $\quad$ Ngo, S. T.; Tam, N. M.; Pham, M. Q.; Nguyen, T. H., Benchmark of Popular Free Energy Approaches Revealing the Inhibitors Binding to SARS-CoV-2 Mpro. J. Chem. Inf. Model. 2021.

49. Ngo, S. T., Estimating the ligand-binding affinity via $\lambda$-dependent umbrella sampling simulations. J. Comput Chem 2021, 42, 117-123.

50. Darden, T.; York, D.; Pedersen, L., Particle mesh Ewald: An $N \cdot \log (\mathrm{N})$ method for Ewald sums in large systems. J. Chem. Phys. 1993, 98 (12), 10089-10092.

51. Papaleo, E.; Mereghetti, P.; Fantucci, P.; Grandori, R.; De Gioia, L., Free-Energy Landscape, Principal Component Analysis, and Structural Clustering to Identify Representative Conformations from Molecular Dynamics Simulations: The Myoglobin Case. J Mol Graph Model 2009, 27 (8), 889-899.

52. Marklund, Erik G.; Degiacomi, Matteo T.; Robinson, Carol V.; Baldwin, Andrew J.; Benesch, Justin L. P., Collision Cross Sections for Structural Proteomics. Structure 2015, 23 (4), 791-799.

53. Ngo, S. T.; Nguyen, P. H.; Derreumaux, P., Stability of A $\beta 11-40$ Trimers with Parallel and Antiparallel $\beta$-Sheet Organizations in a Membrane-Mimicking Environment by Replica Exchange Molecular Dynamics Simulation. J. Phys. Chem. B 2020, 124 (4), 617-626.
54. Sikora, M.; von Bülow, S.; Blanc, F. E. C.; Gecht, M.; Covino, R.; Hummer, G., Computational epitope map of SARSCoV-2 spike protein. PLoS Comput. Biol. 2021, 17 (4), e1008790.

55. Mu, Y.; Nguyen, P. H.; Stock, G., Energy Landscape of a Small Peptide Revealed by Dihedral Angle Principal Component Analysis. Proteins: Struct., Funct., Bioinf. 2005, 58 (1), 45-52.

56. Ngo, S. T.; Phan, H. N.; Le, C. N.; Ngo, N. C. T.; Vu, K. B.; Tung, N. T.; Luu, C. X.; Vu, V. V., Fine Tuning of the Copper Active Site in Polysaccharide Monooxygenases. J. Phys. Chem. B 2020, 124 (10), 1859-1865.

57. Zwanzig, R. W., High-temperature equation of state by a perturbation method. I. nonpolar gases. J. Chem. Phys. 1954, 22 (8), 1420-1426.

58. Kirkwood, J. G., Statistical Mechanics of Fluid Mixtures. J. Chem. Phys. 1935, 3 (5), 300-313.

59. Leonis, G.; Steinbrecher, T.; Papadopoulos, M. G., A Contribution to the Drug Resistance Mechanism of Darunavir, Amprenavir, Indinavir, and Saquinavir Complexes with HIV1 Protease Due to Flap Mutation I50V: A Systematic MMPBSA and Thermodynamic Integration Study. J. Chem. Inf. Model. 2013, 53 (8), 2141-2153.

60. Srinivasan, J.; Cheatham, T. E.; Cieplak, P.; Kollman, P. A.; Case, D. A., Continuum Solvent Studies of the Stability of DNA, RNA, and Phosphoramidate-DNA Helices. J. Am. Chem. Soc. 1998, 120 (37), 9401-9409.

61. Kollman, P. A.; Massova, I.; Reyes, C.; Kuhn, B.; Huo, S.; Chong, L.; Lee, M.; Lee, T.; Duan, Y.; Wang, W.; Donini, O.; Cieplak, P.; Srinivasan, J.; Case, D. A.; T.E. Cheatham, I., Calculating Structures and Free Energies of Complex Molecules: Combining Molecular Mechanics and Continuum Models. Acc. Chem. Res. 2000, 33 (12), 889-897.

62. Siebenmorgen, T.; Zacharias, M., Evaluation of Predicted Protein-Protein Complexes by Binding Free Energy Simulations. J. Chem. Theory Comput. 2019, 15 (3), 2071-2086.

63. Ngo, S. T.; Nguyen, T. H.; Tung, N. T.; Nam, P. C.; Vu, K. B.; Vu, V. V., Oversampling Free Energy Perturbation Simulation in Determination of the Ligand-Binding Free Energy. J. Comput. Chem 2020, 41 (7), 611-618.

64. Pham, M. Q.; Vu, K. B.; Han Pham, T. N.; Thuy Huong, L. T.; Tran, L. H.; Tung, N. T.; Vu, V. V.; Nguyen, T. H.; Ngo, S. T., Rapid prediction of possible inhibitors for SARSCoV-2 main protease using docking and FPL simulations. RSC Adv 2020, 10 (53), 31991-31996.

65. Tam, N. M.; Nam, P. C.; Quang, D. T.; Tung, N. T.; Vu, V. V.; Ngo, S. T., Binding of Inhibitors to the Monomeric and Dimeric SARS-CoV-2 Mpro. RSC Adv 2021, 11, 2926-2934.

66. Tam, N. M.; Pham, M. Q.; Ha, N. X.; Nam, P. C.; Phung, H. T. T., Computational Estimation of Potential Inhibitors from Known Drugs Against the Main Protease of SARS-CoV-2. RSC Adv 2021, 11 (28), 17478-17486. 
Table of Contents Only

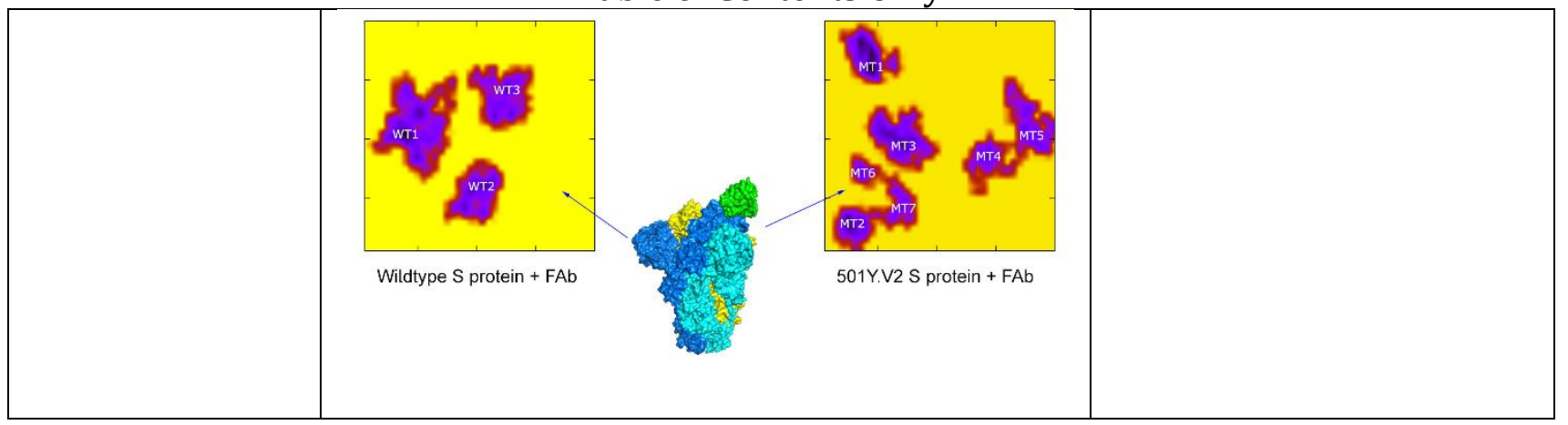

